Journal of the Operations Research

Society of Japan

2005, Vol. 48 , No. 1, 57-70

\title{
A VERIFICATION OF THE END OF THE COLD WAR USING DEA
}

\author{
Ken Nakabayashi Kaoru Tone \\ National Graduate Institute for Policy Studies
}

(Received February 23, 2004; Revised August 31, 2004)

\begin{abstract}
This paper introduces a new index - the 'relative-military index,' which is capable of evaluating a nation's dependence on military forces. We also measured this index by applying data envelopment analysis (DEA) to real-life data, and verified two inferences drawn from Dr. Kissinger's historical description of the post-Cold War world. Our study demonstrates that DEA could be useful in testing hypotheses in the social sciences, especially in the field of International Relations.
\end{abstract}

Keywords: DEA, Malmquist productivity index, military, Cold War, time series analysis

\section{Introduction}

More than 10 years have passed since the former Soviet Union collapsed in 1991. The end of the Cold War was a significant turning point in international relations, as well as for many nations' security environments. Many researchers took an interest in this major development and attempted various forecasts on direction of the post-Cold War world. There have been plenty of studies in descriptive styles for these prospects, whereas, as far as we know, there have been only a handful studies applying quantitative approaches to this historical event.

In our study we try to verify the inferences drawn from a specific prospect using data envelopment analysis (DEA) and the panel data over 14 years (from 1984 to 1997). We suppose that the Cold War ended at the Malta conference in December of 1989, and analyze the changes from the Cold War period (1984-1990) to the post-Cold War period (1990-1997). Concerning the start year 1984, around that time the tension between east and west reached an apex. Concerning the end year 1997, Roberts [8] remarked that "1995 marks the end of the post-cold war era." We will refer to this end period problem later in our paper.

In our attempt we present a new index - the 'relative-military index,' which is measured by the relationship between conventional military forces and the degree of a nation's economic standing, population and territory. Since such an index is capable of evaluating a nation's dependence on military forces, it could be useful in the field of International Relations.

Concerning the forecasts for the post-Cold War world, we would like to introduce two famous opposing views by Francis Fukuyama [2] and Samuel P. Huntington [3]. Fukuyama predicted that the ending of the Cold War signaled the end of the world's last major conflict and the end point of mankind's ideological evolution. He also predicted that the world's societies would maintain their peace, freedom, and stability indefinitely. Opposite to such an optimistic prospect, Huntington viewed the occurrence of conflicts between civilizations as inevitable because of substantially different value systems. He predicted that the primary political actors in the 21 st century would be civilizations, which were mostly divided along 
religious lines.

From an ideological perspective, these forecasts could be useful in presenting a long-range theme, but they do not enable us to conduct scientific verification. For example, despite the Iraq War, Fukuyama might counter that such a conflict was only a bump on the road to a peaceful world. In our study we would like to follow a more pragmatic and data-oriented approach so as to grasp nations' behaviors as clear trends. For this purpose, therefore, we cite a paragraph in Henry A. Kissinger [6]. We can draw the following two inferences from Kissinger's description (which is cited in Section 5 of this paper) concerning the end of the Cold War.

The 1st inference: The relative military power of the United States and Russia would decline whereas that of Japan would rise in the post-Cold War world.

The 2nd inference: Military, political and economic potential are likely to grow more congruent and more symmetrical in the post-Cold War world.

In these inferences, which contain political and quantitative viewpoints, we can find a good opportunity to apply data analysis methodology, and can expect to acquire our own policy implications because the 1st one refers to Japan's national security policy.

We use two variants of DEA models. One is the Slacks-based Measure of Super-Efficiency (Super-SBM) model of Tone [10], and the other is the Slacks-based Malmquist model of Tone [11]. The former model has recently drawn closer attention as a superior index for productivity evaluation in the presence of slacks, and the latter model calculates the Malmquist (productivity) index using the Super-SBM scheme.

The rest of the paper unfolds as follows. In Section 2 we explain in detail our new index, - the 'relative-military index.' Section 3 analyses the relationship between the various elements of a nation's power and its military forces. In Section 4 we present the decision making units (DMUs), the input/output items, the sources of data and models. Section 5 attempts to verify the two inferences drawn from Kissinger's description and examines the results. Finally, some concluding remarks follows in Section 6.

\section{New Index - 'Relative-Military Index (RMI)'}

Kim and Hendry [5] presented a new index - the 'net-burden index' and applied the DEA methodology to the burden-sharing problem among the NATO allies. Referring to their study, the 'relative-military index (RMI)' also applies DEA to problems in the field of International Relations. This index is designed to capture the essence that is enumerated in the third item (which is given below) of the "Basic Policy on National Defense" by the Japanese National Defense Council and Cabinet in 1957.

"To develop incrementally the effective defense capabilities necessary for self-defense, in accordance with the nation's resources and the prevailing domestic situation" ([4], p.282)

It seems plausible that the nation's level of the military forces is, partially at least, related to the nation's resources. The reason is that every nation takes the volume of its resources into account as a constraint on its military force buildup or the size of objects to be protected while deciding upon the overall level of military forces for national security policy. It is reasonable to expect that a nation with abundant resources has a large military force if there is a positive correlation between the nation's resources and the military forces (this hypothesis is verified later). It also might be inefficient for a nation to have too big a defense budget relative to its resources. Hence, we could measure the nation's 'relativemilitary' using DEA by treating each nation as a distinct decision making unit (DMU), 
various nation's resources as outputs, and military forces as inputs, as summarized in the following equation:

$$
\text { nation's relative-military index }(\mathrm{RMI})=\frac{\text { nation's resources }}{\text { nation's military forces }} \text {. }
$$

This RMI is capable of evaluating a nation's dependence on its military forces. That is to say, the high/low index score indicates that the nation's 'dependence on military forces (DMF)' is low/high. Originally, DEA evaluates relative efficiency associated with input resources and produced outputs [1]. Hence, the RMI represents the relative efficiency of a nation's military forces.

\section{Selection of Nation's Resources}

Referring to the following three works (we have highlighted here only the main results), we selected three quantitative indicators viz. Economic potential (GNP), Territorial area and Population as the nation's resources. It is reasonable to expect that a nation with a large quantity of these three items has a large number of military forces.

1. Survey of current studies on national power

We surveyed 14 studies (eight foreign \& six domestic) on national power and could confirm that the three underlined items above were generally perceived to be included in the elements of nation's power.

2. Investigation of Japan's national security policy

We investigated the various policy speeches of Japanese government from 1945 to 1993 and the description of Japanese defense in the white papers. We concluded that the three underlined items above might become both constraints on the defense buildup and the objects to be protected.

3. Statistical hypothesis test using real-life panel data

Using the data of 158 nations, we calculated the Spearman's rank correlation coefficients for each underlined item above with defense expenditure and their corresponding $t$ statistics. The null hypothesis considered here is: There is no correlation between national defense expenditure and GNP, territorial area, population, respectively. The results are reported in Table 1 . All three null hypotheses are rejected at $0.1 \%$ level of significance.

Table 1: Rank correlation coefficients and their corresponding t-statistics

\begin{tabular}{crrr}
\hline & $\begin{array}{r}\text { Defense expenditure } \\
- \text { GNP }\end{array}$ & $\begin{array}{r}\text { Defense expenditure } \\
- \text { Territorial area }\end{array}$ & $\begin{array}{r}\text { Defense expenditure } \\
\text { - Population }\end{array}$ \\
\hline $\begin{array}{c}\text { Rank correlation } \\
\text { coefficient }\end{array}$ & 0.921 & 0.337 & 0.629 \\
\hline $\mathrm{t}$ & 29.427 & & 10.109 \\
\hline
\end{tabular}

\section{The Framework of Analysis}

Here we present the DMUs, the Input - Output (I-O) items, the sources of data and models.

\subsection{DMUs}

We focused on the United States, Russia and Japan in relation to Kissinger's 1st inference. We also picked up four major countries in Europe viz. the United Kingdom, Germany, 
France and Italy, the four major countries in Southeast Asia viz. Thailand, Indonesia, Vietnam and the Philippines, three major countries in East Asia viz. South Korea, North Korea and China (which includes Taiwan), three major countries in the Middle East viz. Egypt, Iran and Iraq, and India in South Asia, as summarized in Table 2. Israel in the Middle East was first considered, but it was dropped because its military manpower is not constant in its particular mobilization system.

Table 2: 18 countries analyzed in our study

\begin{tabular}{ll}
\hline Region & Country \\
\hline North America & The U.S. \\
\hline Europe & Russia, The U.K., Germany, France, Italy \\
\hline East Asia & Japan, South Korea, North Korea, China \\
\hline Southeast Asia & Thailand, Indonesia, Vietnam, The Philippines \\
\hline Middle East & Egypt, Iran, Iraq \\
\hline South Asia & India \\
\hline
\end{tabular}

We consider both the former Soviet Union and Russia as one DMU (Soviet Lnion until 1992 and Russia after 1993). Similarly, we consider both West Germany and Germany as one DMU (West Germany until 1990 and Germany after 1991).

We choose 18 countries from all regions of the world except Latin America, Africa and Oceania. We decided that Latin America and Africa have not had close relations to the Cold War structure. Though Australia in Oceania was considered, it was dropped because its index score evaluated by our scheme was found to be exceptionally high and hence Australia occupied the entire frontier. In DEA evaluations, we have to avoid an efficient frontier spanned by an exceptionally efficient DML (outlier).

\subsection{Input and output (I-O) items}

As stated above, the three output items considered in our study are 'GNP,' 'Territorial area' and 'Population.'

As for input items, we first tried to employ defense expenditure and the physical amount of military forces. However, since the reliability of the data on the defense expenditure of the Communist countries is low, we decided to drop it and consider only the latter: the physical amount of the military forces. They are represented by Army forces, Naval tonnage and Number of combat aircraft. Nuclear weapons are excluded from our data analysis. Instead, we survey the nuclear stockpiles of the L.S. and Russia later in our paper. Hence we employed three inputs and three outputs as follows.

Input: Army forces, Naval tonnage, Number of combat aircraft.

Output: GNP, Territorial area, Population.

\subsection{Sources of data}

The panel Input/Output data of 18 nations over 14 years (from 1984 to 1997) are considered.

1. Real GNP (the base price fiscal 1990)

The United Nations, Statistical Yearbook, 40th issue (1993) and 44th issue (1997).

2. Population

The United Nations, Demographic Yearbook, 45th issue (1993) and 49th issue (1997).

3. Territorial area

The Tsuneta Yano Memorial Society, The data/charts of nations of the world (in Japanese), 1988-89 and 2000-01. 
4. Amount of the forces

Asagumo Press, Defense Handbook (in Japanese), from 1985 to 1998.

Japan Defense Agency, Defense of Japan, from 1985 to 1998.

\subsection{Models}

We have used in our work two variants of DEA models, i.e., the Super-SBM model and the Slacks-based Malmquist model.

The Super-SBM model is considered superior on two counts: 1) in the presence of slacks (input surpluses or output shortfalls) and 2) in discriminating among the best performers. Concerning the problem of slacks, one important property that a DEA measure should ideally satisfy is that when a DML's input increases or output decreases, its score value should decrease. The DEA scores in basic models, e.g., CCR and BCC, do not possess this property. However, the SBM measure [9] has this property.

In the basic DEA models, the best performers have efficiency score unity and there are usually plural DMUs which have this "efficient status." However, the Super-SBM model removed the upper bound ' 1 ' of the score and thus we can rank the best performers. The DEA score computed in this model is called 'super-efficiency' (see Appendix A concerning this calculation).

The Malmquist model calculates the Malmquist index (MI), which was first introduced by Sten Malmquist [7]. The MI is obtained as the composite measure of 'Catch-up' and 'Frontier shift,' and is useful to accurately determine the resultant changes in performance over time. In the non-parametric framework, the MI is measured by means of DEA technology (see Appendix B). The Slacks-based Malmquist model computes the MI using the Super-SBM scheme, which also has the above-mentioned two advantages.

There are six types of both the Super-SBM model and the Slacks-based Malmquist model, as shown in Table 3. There are two options: 1. Orientation - whether the score is measured from input-oriented/output-oriented or non-oriented model, and 2. Returns to scale (RTS) - whether the assumption of constant returns to scale (CRS) or variable returns to scale (VRS) is maintained in each orientation.

Table 3: Six types of Super-SBM and Malmquist models

\begin{tabular}{crrr}
\hline RTS \Orientation & Input-oriented & Output-oriented & Non-oriented \\
\hline CRS & Super SBM-I-C & Super SBM-O-C & Super SBM-C \\
& Malmquist-I-C & Malmquist-O-C & Malmquist-C \\
\hline VRS & Super SBM-I-V & Super SBM-O-V & Super SBM-V \\
& Malmquist-I-V & Malmquist-O-V & Malmquist-V \\
\hline
\end{tabular}

We have used the input-oriented model in our study, since a nation's resources (outputs) are not easily adjustable compared with the military forces. We first intended to use both the CRS model and the VRS model. However, infeasible LP problems occurred for some of the DMUs, such as the U.S., Russia and China when we used the VRS model in the calculation of Super SBM and Malmquist indexes. The reason is that these countries are found to have very high values in some of the output parameters (e.g., the U.S. in GNP, Russia in territorial area, China in population) compared to the other countries. Therefore, we have chosen the CRS models, i.e., the Super SBM-I-C model and the Malmquist-I-C model. 


\section{Analysis}

We now present the two inferences drawn from Dr. Kissinger's description (given below) concerning the end of the Cold War, and attempt to verify them using DEA models.

\subsection{Setting the problems}

Henry A. Kissinger was a member of the faculty of Harvard University, served as Assistant to the President for National Security Affairs in the Nixon Administration, and the Secretary of State concurrently in the Ford Administration. He is known to the public in many ways viz. as a scholar, a politician, a strategist, and so on. To quote Kissinger [6] the following:

"In the Cold War world, the traditional concepts of power had substantially broken down. Most of history has displayed a synthesis of military, political, and economic potential, which in general has proved to be symmetrical. In the Cold War period, the various elements of power became quite distinct. The former Soviet Union was a military super power and at the same time, an economic dwarf. It was also possible for a country to be an economic giant but to be militarily irrelevant, as was the case with Japan.

In the post-Cold War world, the various elements are likely to grow more congruent and more symmetrical. The relative military power of the United States will gradually decline. The absence of a clear-cut adversary will produce domestic pressure to shift resources from defense to other priorities - a process which has already started. When there is no longer a single threat and each country perceives its perils from its own national perspective, those societies which had nestled under American protection will feel compelled to assume greater responsibility for their own security. Thus, the operation of the new international system will move toward equilibrium even in the military field, though it may take some decades to reach that point." ([6], p.23)

The two inferences drawn from the above description are

Inference 1: After the end of the Cold War, the U.S. and Russia show an increasing 'relative-military index (RMI)' trend, whereas the trend is opposite in the case of Japan. (It is to be noted here that the low/high RMI reveal high/low 'dependence on military forces (DMF).')

Inference 2: The RMI differentials among nations will become smaller and smaller during the period from the Cold War time to the post-Cold War time.

\subsection{Verification of the 1st inference}

Here we analyze the performance changes of the nations over time using the Malmquist index (MI) and survey the nuclear stockpiles of the U.S. and Russia.

\subsubsection{Analysis using the Malmquist index}

We analyze the performance changes of the nations over time using Malmquist index (MI). We can judge whether the nation's 'relative-military index (RMI)' increases, remains constant or decreases from the various MI values, which are shown in Table 4 (also see Appendix B).

We computed the MI of 18 nations over 14 years and surveyed the time periods where most of the DMU's show RMI increases or decreases. The results are reported in Table 5.

We notice here that the RMI decreased remarkably in the mid-1980s when the tension between east and west reached an apex, and that it increased in many nations during 19901991. This led us to understand that many nations decreased their military forces at the end of the Cold War. 
Table 4: Malmquist index and RMI change

\begin{tabular}{ll}
\hline MI $>1$ & $\begin{array}{l}\text { The RMI increases. } \\
\text { ('Dependence on military forces (DMF)' decreases.) }\end{array}$ \\
\hline $\mathrm{MI}=1$ & The RMI remains constant. \\
\hline $\mathrm{MI}<1$ & $\begin{array}{l}\text { The RMI decreases. } \\
\text { (The DMF increases.) }\end{array}$ \\
\hline
\end{tabular}

Table 5: Key periods of changes in military forces

\begin{tabular}{|c|c|}
\hline $\begin{array}{l}\text { Time periods when more than half } \\
\text { of the nations show RMI } \\
\text { decreases (DMF increases). }\end{array}$ & $\begin{array}{l}\text { Time periods when most of } \\
\text { the nations show RMI } \\
\text { increases (DMF decreases). }\end{array}$ \\
\hline Number of nations & Number of nations \\
\hline $1984-1985$ & $16 / 18(14 / 16)$ \\
\hline $1985-1986$ & $\begin{array}{l}1988-1991 \\
1989-1993\end{array}$ \\
\hline
\end{tabular}

(): Except for Russia and Germany

In order to verify the 1 st inference, we observe the results for an interval of one year in detail, as reported in Table 6.

The MI values of the U.S. and Russia are greater than unity during the post-Cold War period, (1990-1997). The average MI values of the U.S. and Russia in the post-Cold War period are 1.120 and 1.207 respectively. This means both nations have increased their RMI, i.e., decreased their military forces during this time period. The average MI values of Germany and Iraq in the post-Cold War period are also more than 1.1. Germany, a divided nation on the front-line of the East-West confrontation, needed to reinforce its military strength during the Cold War period, and this requirement decreased after the end of the Cold War. Iraq's high MI values after 1990 are largely due to the destruction of many of its forces in the Gulf War.

In the case of Japan, the average MI value in the post-Cold War period is 0.978 , which is less than unity. This means that Japan has decreased its RMI, i.e., increased its military forces during this time period. The average MI values of Thailand and North Korea in the post-Cold War period are also less than 0.98. Thailand, similar to Japan, had a close connection with the U.S. concerning its dependence on military forces to counter the former Soviet Union. In the case of North Korea, the loss of the former Soviet Union's support at the end of the Cold War spurred it to reinforce its military strength in order to maintain the authoritarian system in international isolation.

As expected, the U.S. and Russia show an increasing RMI trend whereas Japan shows a decreasing trend after the end of the Cold War. Thus, we can confirm the validity of our 1st inference.

\subsubsection{Survey of nuclear weapons}

In Figure 1 below, we survey the nuclear stockpiles of the U.S. and Russia because our data analysis did not take nuclear weapons into account. (Data Source: The Bulletin of the Atomic Scientists, Nuclear Notebook: Global nuclear stockpiles, 1945 - 2002; from internet: [www.thebulletin.org])

We can observe that both countries decreased their 'dependence on the nuclear forces' 
Table 6: MI values for an interval of one year

(a) The Cold War period

\begin{tabular}{lccccccc}
\hline Nation & $1984-5$ & $1985-6$ & $1986-7$ & $1987-8$ & $1988-9$ & $1989-90$ & Average \\
\hline The U.S. & 1.003 & 0.999 & 0.997 & 1.007 & 1.022 & 0.997 & 1.004 \\
Russia & 0.987 & 0.993 & 0.958 & 0.983 & 0.998 & 1.089 & 1.001 \\
Japan & 1.092 & 0.972 & 1.035 & 1.000 & 0.973 & 1.017 & 1.015 \\
The U.K. & 0.979 & 1.007 & 1.040 & 1.024 & 1.011 & 1.034 & 1.016 \\
Germany & 0.999 & 1.001 & 0.982 & 1.042 & 1.086 & 1.071 & 1.030 \\
France & 1.026 & 0.988 & 0.973 & 1.031 & 1.063 & 1.025 & 1.018 \\
Italy & 0.844 & 1.125 & 0.965 & 1.041 & 1.033 & 0.991 & 1.000 \\
Thailand & 1.159 & 0.955 & 0.885 & 0.960 & 1.000 & 1.004 & 0.994 \\
Indonesia & 0.998 & 0.943 & 1.035 & 1.025 & 1.144 & 0.939 & 1.014 \\
Vietnum & 0.940 & 1.001 & 1.017 & 0.928 & 0.905 & 1.114 & 0.984 \\
The Philippines & 0.833 & 1.169 & 1.296 & 0.982 & 0.971 & 1.238 & 1.081 \\
South Korea & 1.147 & 0.946 & 1.052 & 1.057 & 1.015 & 0.983 & 1.033 \\
North Korea & 0.981 & 0.976 & 1.076 & 0.992 & 0.944 & 0.940 & 0.985 \\
China & 1.047 & 1.133 & 0.961 & 1.041 & 1.009 & 0.988 & 1.030 \\
Egypt & 0.826 & 0.996 & 1.756 & 1.021 & 1.013 & 1.123 & 1.123 \\
Iran & 1.171 & 1.000 & 1.345 & 1.010 & 0.590 & 0.915 & 1.005 \\
Iraq & 0.373 & 0.840 & 0.936 & 0.968 & 0.948 & 0.981 & 0.841 \\
India & 1.021 & 1.030 & 0.867 & 1.031 & 0.968 & 1.026 & 0.991 \\
\hline Average & 0.968 & 1.004 & 1.065 & 1.008 & 0.983 & 1.026 & 1.009 \\
\hline
\end{tabular}

(b) The post-Cold War period

\begin{tabular}{lcccccccc}
\hline Nation & $1990-1$ & $1991-2$ & $1992-3$ & $1993-4$ & $1994-5$ & $1995-6$ & $1996-7$ & Average \\
\hline The U.S. & 1.021 & 1.074 & 1.160 & 1.070 & 1.073 & 1.196 & 1.245 & 1.120 \\
Russia & 1.170 & 1.093 & 1.097 & 1.335 & 1.264 & 1.335 & 1.155 & 1.207 \\
Japan & 1.004 & 0.950 & 0.974 & 0.887 & 0.967 & 1.093 & 0.975 & 0.978 \\
The U.K. & 1.014 & 1.074 & 1.021 & 1.073 & 1.050 & 1.054 & 1.032 & 1.045 \\
Germany & 1.073 & 1.182 & 1.059 & 1.395 & 1.110 & 0.724 & 1.325 & 1.124 \\
France & 0.998 & 0.995 & 1.034 & 1.024 & 1.045 & 1.039 & 1.115 & 1.036 \\
Italy & 1.034 & 1.027 & 1.047 & 0.993 & 1.086 & 1.030 & 0.965 & 1.026 \\
Thailand & 1.018 & 0.964 & 1.021 & 1.040 & 0.977 & 0.902 & 0.843 & 0.967 \\
Indonesia & 1.051 & 1.053 & 0.999 & 0.957 & 1.107 & 0.999 & 0.837 & 1.000 \\
Vietnum & 1.053 & 1.055 & 1.019 & 1.097 & 1.005 & 1.016 & 1.089 & 1.048 \\
The Philippines & 0.954 & 1.002 & 1.088 & 1.103 & 0.986 & 1.023 & 0.999 & 1.022 \\
South Korea & 1.052 & 1.052 & 0.940 & 1.001 & 1.068 & 1.027 & 1.014 & 1.022 \\
North Korea & 1.007 & 0.925 & 0.935 & 1.026 & 0.992 & 0.912 & 0.998 & 0.971 \\
China & 1.009 & 1.001 & 1.029 & 1.005 & 1.014 & 1.004 & 1.005 & 1.010 \\
Egypt & 1.048 & 1.010 & 1.012 & 0.969 & 0.918 & 0.998 & 0.910 & 0.981 \\
Iran & 1.040 & 1.059 & 0.905 & 0.948 & 0.921 & 0.989 & 0.996 & 0.980 \\
Iraq & 1.498 & 1.543 & 1.000 & 1.000 & 0.831 & 2.253 & 1.035 & 1.309 \\
India & 1.146 & 0.951 & 1.005 & 0.901 & 1.033 & 1.108 & 1.021 & 1.024 \\
\hline Average & 1.066 & 1.056 & 1.019 & 1.046 & 1.025 & 1.095 & 1.031 & 1.048 \\
\hline
\end{tabular}




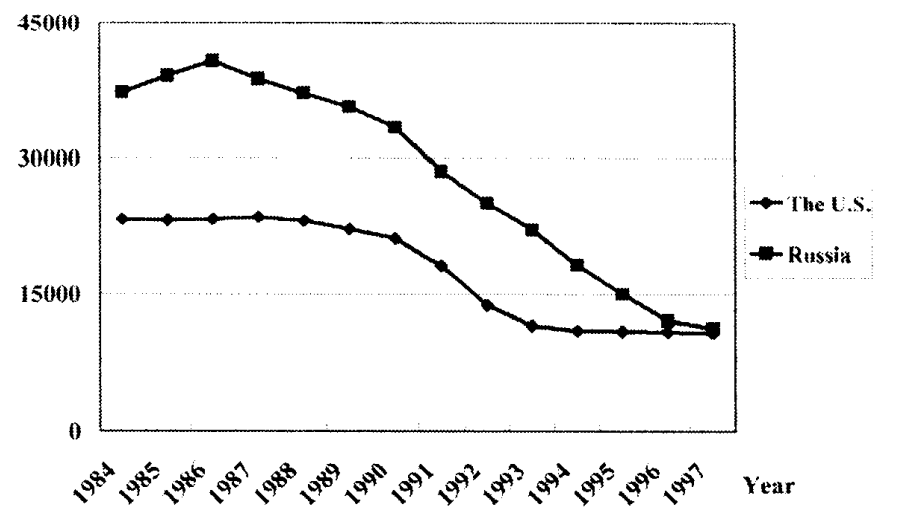

Figure 1: Nuclear stockpiles of the U.S. and Russia

since the end of the Cold War. These results could re-enforce the validity of our 1st inference.

\subsection{Verification of the 2nd inference}

For this purpose, we measured the RMI using the Super SBM-I-C model. We treated each DMU over time as distinct and evaluated the nations' RMI with a total of 252 DMUs (18 nations $\times 14$ years). In order to verify the 2 nd inference, we calculated the coefficient of variation (= standard deviation / average) of the nations' RMI for each year. The results are shown in Figure 2.

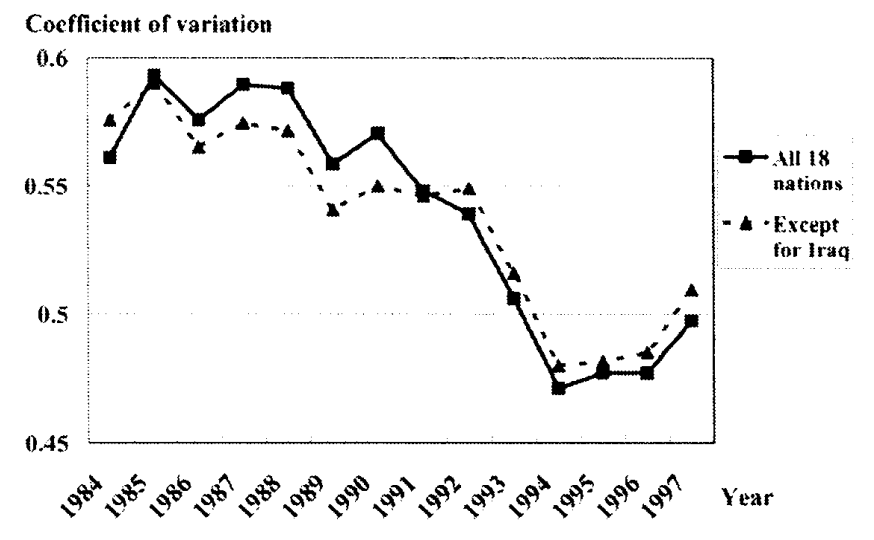

Figure 2: Coefficient of variation of the nations' RMI

The coefficient of variation is highest in the year 1985, (0.59) and lowest in the year $1994,(0.47)$. After this, the trend is seen to be slightly upward. In particular we observe a remarkable decrease in the coefficient of variation during 1990-1994. According to Kissinger's description, this remarkable change reflects a shift from the bipolar system created by the Cold War to the new international system. Our data analysis also shows that the year 1994 is an extreme point. In this year world politics and the international relations might be said to have entered a new phase.

Thus, we can confirm the validity of our 2nd inference until 1994, whereas our results do not show this validity after the year 1994 and suggest the coming of a new era. 


\subsection{Considerations}

We have made an attempt to verify two inferences drawn from Dr. Kissinger's description concerning the symmetry/asymmetry of the synthesis of military, political and economic potential during the period from the Cold War time to the post-Cold War time. Both inferences are confirmed, with the exception of the 2nd inference after the year 1994 .

Were there any turns of events after the year 1994? Though we cannot present a specific event from our data analysis, we here introduce Roberts [8]. "The coming year, 1995, promises to be a significant turning point in the post-cold war international security dynamics," ... "1995 will be a pivotal year" and "1995 marks the end of the post-cold war era." He explained "The year 1995 will be the critical year for the global treaty regime for the control of nuclear, chemical, and biological weapons" and " 1995 will be a year in which each of the major elements of the global political framework are evaluated and refashioned." Certainly, in 1995 the meetings to review and extend the Nuclear Non-Proliferation Treaty (NPT) were held and it was decided to extend the treaty for an indefinite period of time. The participants also adopted a "decision as to the strengthening of a process for a review of the treaty" and a "decision as to principles and targets for nuclear non-proliferation and nuclear disarmament." Many nations were involved in the international effort to promote the cooperative resolution of the common problem in 1995. This change of trend might correspond to the upward move of the index after 1995 in Figure 2.

Next we observe the gradual increase in Japan's military forces in the post-Cold War period. Based on Kissinger's description, we can explain this as follows.

During the Cold War period, both Japan's and America's national security interests were identical because both countries perceived the former Soviet Union as the principal security threat. Therefore, under America's commitment to defend Japan, low military power was sufficient for Japan's own national security during this time period. However, after the end of the Cold War, Japan has had to build up its military forces because Japan could not indefinitely assume that Japan's and America's security interests would remain identical.

This explanation is very convincing until the year 1994. However, the 2nd inference is not valid after the year 1994. Actually, in 1995 the U.S. Department of Defense issued the 3rd East Asia Strategy Report [12] that announced America's commitment to maintain a stable forward presence in the East Asia region, at the existing level of about 100,000 troops, for the foreseeable future. Moreover, in 1996 the U.S. President and Japan's Prime Minister pointed to the importance of democracy, freedom and other values shared by both countries, and signed a document entitled the "Japan-U.S. Joint Declaration on Security: Alliance for the 21st Century," which gave a new framework of security cooperation. Thus, Japan-US security relationship entered a new phase in 1996. It is necessary to conduct a more thorough microanalysis in terms of new roles and missions among these two allies.

\section{Concluding Remarks}

In this paper we presented a new index - the 'relative-military index,' which is capable of evaluating the nation's dependence on military forces. We also measured, using DEA, 'relative-military' trends of 18 nations during the time period from the Cold War era (1984-1990) to the post-Cold War era (1990-1997). We verified two inferences drawn from Dr. Kissinger's widely-acknowledged description and develop an understanding concerning the security environment changes of various nations, including Japan.

We could confirm the validity of Kissinger's description until the year 1994, whereas we could not confirm it during 1994-1997. Our data analysis showed that the year 1994 was 
an extreme point. That is to say, in our analysis the post-Cold War world of Kissinger corresponded to the time period of 1990-1994. Our study also supported Roberts [8], who mentioned "1995 marks the end of the post-cold war era." As historical facts, the global security regime (NPT) and Japan-US security relationship have been reviewed and reinforced since the year 1995 .

Our study demonstrates that DEA could be useful in the field of International Relations. This is accomplished in terms of two major directions. First, we designed a new index, which is computed by the ratio of the weighted sum of a nation's resources to the weighted sum of its conventional military forces. Second, using this index, we could verify and interpret the trends in military forces in and post the Cold War era quantitatively.

From our experience in concluding this study, we are convinced that DEA can be utilized as a powerful means for the test of hypotheses in the social sciences, especially in International Relations. We also hope that our proposed scheme will be applied in many fields of panel data analysis.

\section{References}

[1] W. W. Cooper, L. M. Seiford and K. Tone: Data Envelopment Analysis - A comprehensive text with models, applications, references and DEA-Solver software (Kluwer Academic Publishers, 1999).

[2] F. Fukuyama: The end of history and the last man (The Free Press, 1992).

[3] S. P. Huntington: The clash of civilizations? Foreign Affairs, 72-3 (1993), 22-49.

[4] Japan Defense Agency: Defense of Japan 2001 (2001).

[5] I. Kim and L. C. Hendry: Using DEA to assess NATO burden-sharing. Journal of the Operational Research Society, 49 (1998), 228-236.

[6] H. A. Kissinger: Diplomacy (Simon \& Schuster, 1994).

[7] S. Malmquist: Index numbers and indifference surfaces. Trabajos de Estadistica, 4 (1953), 209-242.

[8] B. Roberts: 1995 and the end of the post-Cold War era. The Washington Quarterly, 18-1 (1995), 5-25.

[9] K. Tone: A slacks-based measure of efficiency in data envelopment analysis. European Journal of Operational Research, 130 (2001), 498-509.

[10] K. Tone: A slacks-based measure of super-efficiency in data envelopment analysis. European Journal of Operational Research, 143 (2002), 32-41.

[11] K. Tone: Malmquist productivity index. In Cooper, Seiford and Zhu (eds.): Handbook on Data Envelopment Analysis (Kluwer Academic Publishers, 2004), Chapter 8, 203227.

[12] The U.S. Department of Defense: United States security strategy for the East AsiaPacific region 1995 (1995).

\section{Appendix A: The Super SBM-I-C Model}

We consider a set of $n$ DMUs (decision making units) which is described by the input and output matrices $X=\left(x_{i j}\right) \in R^{m \times n}$ and $Y=\left(y_{i j}\right) \in R^{s \times n}$, respectively. So, we suppose $n$ DMUs with $m$ inputs and $s$ outputs.

The production possibility set $P$ is defined as

$$
P=\{(x, y) \mid x \geq X \lambda, Y \lambda \geq y, \lambda \geq 0\}
$$


where $\lambda$ is a nonnegative vector in $R^{n}$.

We have an "examinee" or "target" DMU denoted by $\left(x_{o}, y_{o}\right)$ with $x_{o} \in R^{m}$ and $y_{o} \in R^{s}$. The target DML $\left(x_{o}, y_{o}\right)$ is not a member of the evaluator group. However, this does not exclude the possibility that some evaluators coincide with the target by chance. We assume that $X>O$ and $x_{0}>0$.

In order to evaluate the efficiency of the examinee $\left(x_{o}, y_{o}\right)$, we formulate the following linear programming problem with variables $\lambda, s^{-} \in R^{m}$ and $s^{+} \in R^{s}$ :

$$
\begin{aligned}
{[\mathrm{SBM}-\mathrm{I}] \rho_{I}^{*}=\min } & \rho_{I}=1-\frac{1}{m} \sum_{i=1}^{m} s_{i}^{-} / x_{i o} \\
\text { subject to } & x_{o}=X \lambda+s^{-} \\
& y_{o}=Y \lambda-s^{+} \\
& \lambda \geq 0, s^{-} \geq 0, s^{+} \geq 0 .
\end{aligned}
$$

If [SBM-I] has a finite minimum $\rho_{I}^{*}$, then $\left(x_{o}, y_{0}\right)$ belongs to the production possibility set $P$ spanned by the evaluator group. From the assumption $X>O$ and $x_{o}>0$, it holds

$$
1 \geq \rho_{I}^{*}>0 .
$$

The score $\rho_{I}^{*}$ is units invariant. If [SBM-I] has no feasible solution, the examinee $\left(x_{o}, y_{0}\right)$ is positioned outside $P$. In this case, we solve the following problem [Super SBM-I]:

$$
\begin{aligned}
{\left[\text { Super SBM-I] } \delta_{I}^{*}=\min \right.} & \delta_{I}=1+\frac{1}{m} \sum_{i=1}^{m} s_{i}^{-} / x_{i o} \\
\text { subject to } & x_{o} \geq X \lambda+s^{-} \\
& Y \lambda \geq y_{o} \\
& \lambda \geq 0, s^{-} \geq 0 .
\end{aligned}
$$

[Super SBM-I] always has a finite optimum $\delta_{I}^{*}(\geq 1)$.

\section{Appendix B: The Malmquist (Productivity) Index}

The Malmquist index evaluates the efficiency change of a DMU between two time periods. It is defined as the product of "Catch-up" and "Frontier-shift" terms. The catch-up (or recovery) term relates to the degree of efforts that the DMU attained for improving its efficiency, while the frontier-shift (or innovation) term reflects the change in the efficient frontiers surrounding the DMU between the two time periods. We deal with a set of $n$ DMUs $\left(x_{j}, y_{j}\right)(j=1, \cdots, n)$ each having $m$ inputs denoted by a vector $x_{j} \in R^{m}$ and $s$ outputs denoted by a vector $y_{j} \in R^{s}$ over the periods 1 and 2 . We assume $x_{j}>0$ and $y_{j}>0(\forall j)$. The notations $\left(x_{o}, y_{o}\right)^{1}$ and $\left(x_{o}, y_{o}\right)^{2}$ are employed for designating $\mathrm{DML}_{o}$ at the periods 1 and 2, respectively. On the constant returns to scale (CRS) model, the production possibility set $(X, Y)^{t}(t=1$ and 2$)$ spanned by $\left\{\left(x_{j}, y_{j}\right)^{t}\right\}(j=1, \cdots, n)$ is defined by:

$$
(X, Y)^{t}=\left\{(x, y) \mid x \geq \sum_{j=1}^{n} \lambda_{j} x_{j}^{t}, \sum_{j=1}^{n} \lambda_{j} y_{j}^{t} \geq y \geq 0\right\}
$$

where $\lambda$ is a nonnegative vector in $R^{n}$. The production possibility set $(X, Y)^{t}$ is characterized by its frontiers that are composed of $(x, y) \in(X, Y)^{t}$ such that it is not possible to improve any element of the input $x$ or any element of the output $y$ without worsening some other input or output. See [1] for further discussion on this and related subjects. We call this frontier set the frontier technology at the period $t$. 


\section{B.1. Catch-up effect}

The catch-up effect is measured by the following formula.

$$
\text { Catch }- \text { up }=\frac{\text { Efficiency of }\left(x_{o}, y_{o}\right)^{2} \text { wrt the period } 2 \text { frontier }}{\text { Efficiency of }\left(x_{o}, y_{o}\right)^{1} \text { wrt the period } 1 \text { frontier }},
$$

where "wrt" means "with respect to."

We evaluate each element (the efficiency) of the above formula using the appropriate DEA models. A simple single input and output case is illustrated in Figure B-1.

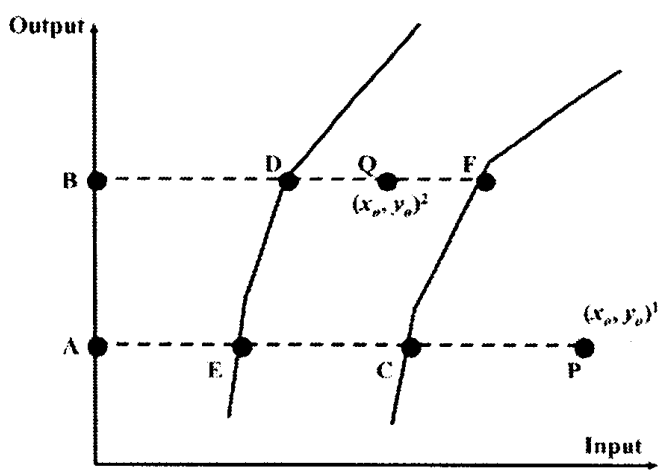

Figure B-1: Catch-up

The catch-up effect (in input-orientation) can be computed as:

$$
\text { Catch-up }=\frac{\mathrm{BD} / \mathrm{BQ}}{\mathrm{AC} / \mathrm{AP}}
$$

(Catch-up) $>1$ indicates progress in the relative efficiency from period 1 to 2 , while (Catch-up) $=1$ and (Catch-up) $<1$ indicate no change and regress in efficiency, respectively.

\section{B.2. Frontier-shift effect}

In addition to the catch-up term, we must take account the frontier-shift (innovation) effect in order to fully evaluate the efficiency change of the DMU, since the catch-up is determined by the efficiencies as measured by the distances from the respective frontiers. In the simple Figure $\mathrm{B}-1$ case, this can be implemented as follows. The reference point $\mathrm{C}$ of $\left(x_{o}, y_{o}\right)^{1}$ moved to $\mathrm{E}$ on the frontier of period 2. Thus, the frontier-shift effect at $\left(x_{o}, y_{o}\right)^{1}$ is evaluated by

$$
\varphi_{1}=\frac{\mathrm{AC}}{\mathrm{AE}}
$$

This is equivalent to

$$
\varphi_{1}=\frac{\frac{\mathrm{AC}}{\mathrm{AP}}}{\frac{\mathrm{AE}}{\mathrm{AP}}}=\frac{\text { Efficiency of }\left(x_{o}, y_{o}\right)^{1} \text { wrt the period } 1 \text { frontier }}{\text { Efficiency of }\left(x_{o}, y_{o}\right)^{1} \text { wrt the period } 2 \text { frontier }} .
$$

The numerator of the $(\mathrm{B}-4)$ right is already obtained in $(\mathrm{B}-1)$. The denominator is measured as the efficiency score of $\left(x_{o}, y_{o}\right)^{1}$ relative to the period 2 frontier. Similarly, the frontier-shift effect at $\left(x_{o}, y_{o}\right)^{2}$ is expressed by

$$
\varphi_{2}=\frac{\frac{\mathrm{BF}}{\mathrm{BQ}}}{\frac{\mathrm{BD}}{\mathrm{BQ}}}=\frac{\text { Efficiency of }\left(x_{o}, y_{o}\right)^{2} \text { wrt the period } 1 \text { frontier }}{\text { Efficiency of }\left(x_{o}, y_{o}\right)^{2} \text { wrt the period } 2 \text { frontier }}
$$


Using $\varphi_{1}$ and $\varphi_{2}$, we define "Frontier-shift" effect by their geometric mean as:

$$
\text { Frontier-shift }=\varphi=\sqrt{\varphi_{1} \varphi_{2}} \text {. }
$$

(Frontier-shift) $>1$ indicates progress in the frontier technology around the $\mathrm{DMC}_{o}$ from period 1 to 2 , while (Frontier-shift) $=1$ and (Frontier-shift) $<1$ indicate the status quo and regress in the frontier technology, respectively.

\section{B.3. Malmquist index}

The "Malmquist index" is obtained as the product of (Catch-up) and (Frontier-shift).

$$
\text { Malmquist index }=(\text { Catch-up }) \times(\text { Frontier-shift }) \text {. }
$$

We employ the following notation for the efficiency score of DMU $\left(x_{o}, y_{o}\right)^{t_{1}}$ measured by the frontier technology $t_{2}$.

$$
\delta^{t_{2}}\left(\left(x_{o}, y_{o}\right)^{t_{1}}\right)\left(t_{1}=1,2 \text { and } t_{2}=1,2\right) .
$$

Using this notation, the catch-up effect $(C)$ in $(B-1)$ can be expressed as:

$$
C=\frac{\delta^{2}\left(\left(x_{o}, y_{o}\right)^{2}\right)}{\delta^{1}\left(\left(x_{o}, y_{o}\right)^{1}\right)} \text {. }
$$

The frontier-shift effect is described as:

$$
F=\left[\frac{\delta^{1}\left(\left(x_{o}, y_{o}\right)^{1}\right)}{\delta^{2}\left(\left(x_{o}, y_{o}\right)^{1}\right)} \times \frac{\delta^{1}\left(\left(x_{o}, y_{o}\right)^{2}\right)}{\delta^{2}\left(\left(x_{o}, y_{o}\right)^{2}\right)}\right]^{1 / 2} .
$$

As the product of $C$ and $F$, we obtain the formula for the Malmquist index as follows:

$$
M I=\left[\frac{\delta^{1}\left(\left(x_{o}, y_{o}\right)^{2}\right)}{\delta^{1}\left(\left(x_{o}, y_{o}\right)^{1}\right)} \times \frac{\delta^{2}\left(\left(x_{o}, y_{o}\right)^{2}\right)}{\delta^{2}\left(\left(x_{o}, y_{o}\right)^{1}\right)}\right]^{1 / 2}
$$

This last expression gives another definition/interpretation of $M I$, i.e., the geometric means of the two efficiency ratios: the one, the efficiency change measured by the period 1 technology and the other, the efficiency change measured by the period 2 technology.

As can be seen from these formulae, the $M I$ consists of four terms: $\delta^{1}\left(\left(x_{o}, y_{o}\right)^{1}\right)$, $\delta^{2}\left(\left(x_{o}, y_{o}\right)^{2}\right), \delta^{1}\left(\left(x_{o}, y_{o}\right)^{2}\right)$ and $\delta^{2}\left(\left(x_{o}, y_{o}\right)^{1}\right)$. The first two relate with measurements within the same time period, while the last two are obtained from intertemporal comparisons.

(Malmquist index) $>1$ indicates progress in the total factor productivity of the $\mathrm{DMU}_{o}$ from period 1 to 2 , while (Malmquist index) $=1$ and (Malmquist index) $<1$ indicate the status quo and regress in the total factor productivity, respectively.

Ken Nakabayashi

National Graduate Institute

for Policy Studies

2-2 Wakamatsu-cho, Shinjuku-ku,

Tokyo 162-8677, Japan

E-mail: ken@stu.grips.ac.jp 